\title{
Traumatic Brain Injury: Comparison of Computed Tomography Findings in Pediatric and Adult Populations
}

\author{
Madhur Choudhary ${ }^{1} \quad$ Khursheed Alam Khan ${ }^{1} \quad$ Nandkishore Gora ${ }^{1} \quad$ Achal Sharma ${ }^{1}$ Virendra Deo Sinha ${ }^{1}$ \\ ${ }^{1}$ Department of Neurosurgery, Sawai Man Singh Medical College, \\ Jaipur, Rajasthan, India \\ Address for correspondence Khursheed Alam Khan, MCh, \\ Department of Neurosurgery, Sawai Man Singh Medical College, Jaipur, \\ Rajasthan 302007, India (e-mail: kkneuro15@gmail.com).
}

Indian J Neurosurg:2020;9:151-156

\begin{abstract}
Keywords

- traumatic brain injury

- Rotterdam score

- computed

tomography scan

Introduction Traumatic brain injury (TBI) is a global health issue, accounting for a significant number of adult and pediatric deaths and morbidity. Computed tomography $(\mathrm{CT})$ is an important diagnostic modality for TBI. The primary goal of this study was to determine if there were any significant radiological differences in CT brain findings between adult and pediatric populations.

Materials and Methods Data of individual patients were collected from admission to discharge/death, which included various parameters in terms of demographics, mechanism of injury, and patient outcome which were later analyzed. A total of $1,150 \mathrm{TBI}$ patients were enrolled in the study.

Results The most common mode of injury in adults is road traffic accident (RTA) followed by fall from height (FFH), while in pediatrics it is vice versa. Findings of basal cisterns on CT brain were found to be statistically significant in both groups; $65 \%$ adults and $71 \%$ pediatrics had only one abnormal CT finding. Most common combination CT finding in adults was acute subdural hematoma (ASDH) and basal cistern abnormality, while in pediatrics it was traumatic subarachnoid hemorrhage (SAH) and contusion. Rotterdam score (based on CT brain findings) was significantly lower for pediatric age group compared with adults. It was $2.2 \pm 0.85$ for adults and $1.99 \pm 0.74$ for pediatrics, which was statistically significant $(p<0.001)$.

Conclusions The Rotterdam score has immense predictive power for prognostication of mortality status. Pediatric age group has better prognosis in terms of survival as compared with adults, thus justifying the role of Rotterdam CT score for mortality risk stratification in providing clinical care.
\end{abstract}

\section{Introduction}

Traumatic brain injury (TBI) is a global health issue with an estimated incidence rate of 100 per 100,000 persons and 52,000 annual deaths. ${ }^{1}$ It results in a significant number of adult and pediatric deaths and morbidity. TBI has been referred to as the "silent epidemic" by the Centers for Disease Control and Prevention (CDC) and others, because of its vast incidence and pressing need for additional research. ${ }^{2}$ With

DOI https://doi.org/ 10.1055/s-0040-1708066 ISSN 2277-954X. the increasing use of vehicles, there has been a tremendous increase in the incidence of TBI worldwide. ${ }^{3}$ TBI is a major health problem worldwide, and any measure reducing mortality and morbidity associated with the same would lead to significant benefit in socioeconomic terms. ${ }^{4}$ Globally, children constitute only $33.3 \%$ of the world population, but the great majority (88.7\%) of these children live in developing nations. ${ }^{5,6}$ A unifying characteristic of developing countries is the improper injury prevention programs. ${ }^{7}$ In India, TBI is mostly caused

(c) 2020. Neurological Surgeons' Society of India.

This is an open access article published by Thieme under the terms of the Creative Commons Attribution-NonDerivative-NonCommercial-License, permitting copying and reproduction so long as the original work is given appropriate credit. Contents may not be used for commercial purposes, or adapted, remixed, transformed or built upon. (https://creativecommons.org/licenses/by-nc-nd/4.0/)

Thieme Medical and Scientific Publishers Pvt. Ltd., A-12, 2nd Floor, Sector 2, Noida-201301 UP, India 
by road traffic injuries (60\%), followed by falls (20-25\%) and violence. ${ }^{8,9}$ Although there have been numerous studies of TBI which examined and included the general population, but in this population-based study, we are particularly studying the adult and pediatric age group population in terms of characteristics of TBI. Clinical outcomes for pediatric TBI have not significantly improved over the past decade, suggesting that targeted research is necessary. ${ }^{10-12}$

Computed tomography (CT) scan plays a very important role as a diagnostic modality for TBI. It is a very important diagnostic tool that is used to classify the type of injury and associated neurocritical care intervention needed. It ultimately affects the functional outcome of patients and depicts the survival rate. In the context of the huge burden of TBI, which is associated with the lack of sufficient epidemiological data, adequate workup is needed. There have been a lot many studies which depict that the biomechanics of TBI are significantly different in adults and children. ${ }^{13-16}$ Thus, enabling the need of studying the pattern of intracranial injury in pediatric age group and comparing it with the adult population. This comparison would ultimately influence the clinical management of patient and outcome. A more thorough understanding of pediatric TBI CT findings is necessary to improve our clinical approach to diagnosis and treatment, which may prove valuable in designing future clinical trials.

\section{Aim}

In this study, our primary goal was to determine if there were any significant radiological differences between adult and pediatric populations admitted at a Level 1 trauma center of Northwest India at SMS Medical college, Jaipur, India. Our secondary objective was to study the demographics, injury characteristics, severity of injury, and outcome of TBI in pediatric age group compared with the adult age group. Such analysis would be valuable for emphasizing this significant problem in this part of the developing world and could serve as a cornerstone for initiation of injury prevention programs in developing nations.

\section{Materials and Methods}

This prospective study was conducted in the Department of Neurosurgery, Institute of Traumatology, SMS Medical College, Jaipur, Rajasthan, India.

Study period-Between July 2016 and December 2017.

Study group-A total of 1,150 patients were enrolled in the study after ethical clearance from the ethical committee of SMS Medical College, Jaipur, Rajasthan, India. The pediatric age group was defined as patients having an age less than or equal to 16 years.
All patients were managed as per the head injury protocol of the institute. Data of individual patients were collected from admission to discharge/death as per performa which includes various parameters in terms of demographics, mechanism of injury, and patient outcome. The data collected was age, sex, mode of injury, mode of transportation, duration in reaching hospital, radiological assessment, Glasgow coma scale (GCS)on admission and discharge, injury severity score (ISS), length of hospital stay, and incidence of polytrauma.

Inclusion criteria-Patients included in this registry met at least one of the following two criteria that prompted neurosurgical consultation: (1) TBI suspected due to clinical history, clinical symptoms or signs of neurological deficits on physical examination; or (2) abnormal CT findings after trauma.

Exclusion criteria-Severe pre-existing neurological disorder that would confound outcome assessments and any penetrating head injury.

\section{Radiographic Data}

The initial post injury CT scan was reviewed by neurosurgery house staff at the time of initial consultation; for patients who were transferred from an outside hospital, the scan obtained at the transferring institution was reviewed as the initial scan. A form was completed at the time of initial evaluation to document the following intracranial hemorrhage patterns: epidural hematoma $(\mathrm{EDH})$, subdural hematoma $(\mathrm{SDH})$, subarachnoid hemorrhage (SAH), and skull fractures. Basal cisterns were classified as open, compressed, or absent, and midline shift was classified as $<5$ or $\geq 5 \mathrm{~mm}$. These variables were used to calculate a Rotterdam CT score for each patient. ${ }^{17,18}$

\section{Rotterdam Score}

The Rotterdam CT score of TBI is aimed at improving prognostic evaluation of patients admitted with acute TBI. It includes four independently scored elements. Like the Marshall system, ${ }^{17}$ it includes the following: (1) degree of basal cistern compression and (2) degree of midline shift. It does not, however, include contusions, but rather restricts mass lesions to (3) epidural hematomas and adds (4) intraventricular and/or subarachnoid blood. Each of these is given a score, and these scores are tallied, with the addition of 1 to the total. ( - Table $\mathbf{1}$ )

\section{Prognosis}

In adults, the mortality at 6 months increases with the score. ${ }^{17}$ Children have lower mortality withlower Rotterdam scores (scores 2 and 3), and higher mortality with higher scores (scores 4 to 6$){ }^{18}$

Table 1 Rotterdam score

\begin{tabular}{|l|l|l|l|}
\hline Basal cisterns & Midline shift & Epidural mass lesion & Intraventricular blood or traumatic SAH \\
\hline $0:$ normal & $0:$ no shift or $\leq 5 \mathrm{~mm}$ & $0:$ present & $0:$ absent \\
\hline 1: compressed & $1:$ shift $>5 \mathrm{~mm}$ & $1:$ absent & $1:$ present \\
\hline 2: absent & & & \\
\hline
\end{tabular}

Abbreviation: SAH, subarachnoid hemorrhage. 


\section{Statistical Analysis}

Statistical analyses were conducted using computer software (SPSS Trail version 23 and primer). The qualitative data were expressed in proportion and percentages, and the quantitative data expressed as mean and standard deviations. The difference in proportion was analyzed by using chi square test, and the difference in means were analyzed by using student "t" test. Significance level for tests were determined as 95\% $(p<0.05)$.

\section{Results}

\section{Demographic Characteristics}

Between July 2016 and December 2017, out of 1150 patients, $211(18.35 \%)$ were classified as pediatric (age < 16 years) and 939 (81.65\%) were classified as adults. There were 795 males and 145 females in the adult population, and 162 males and 49 females in the pediatric population. The male:female ratio was 5.48:1 for adults and 3.31:1 for pediatrics (-Table 2).

\section{Mechanism of Injury}

The most common mode of injury in adults is road traffic accident (RTA), followed by FFH (fall from height), while in pediatrics, the most common mode is FFH followed by RTA. The incidence of other modes of injury in adults and pediatrics is specified in (-Table 2 ). The mechanism of injury was significantly different between the two groups.

\section{Computed Tomography Findings}

A comparison of the CT findings in both the population groups is stated in - Table 3 . The difference in findings of basal cistern on CT brain was significant in both groups, while CT finding of traumatic SAH and EDH were not significant. Miscellaneous findings of midline shift, SDH, contusion, pneumocephalous, and depressed fracture was significant in both the groups.

\section{Presence of Multiple CT Findings After TBI}

A significant percentage of adults and pediatrics (65 and $71 \%$, respectively)had only one abnormal CT finding; $28 \%$ patients had two abnormal CT findings in combination, 10\% had three, and $4 \%$ had four abnormal CT findings. The most common combination CT found in adults was acute SDH and basal cistern abnormality, while in pediatrics it was traumatic SAH and contusion ( $\mathbf{- T a b l e ~} \mathbf{2}$ ).

\section{Rotterdam Score}

The Rotterdam score was significantly lower for the pediatric age group compared with adults. It was $2.2 \pm 0.85$ for adults and $1.99 \pm 0.74$ for pediatrics, which was statistically significant with a $p<0.001$. This signifies lower mortality rates in pediatrics and higher mortality rates in adult head injury patients ( - Table $\mathbf{3}$ ).

\section{Discussion}

TBI is an emerging global health issue in developing nations. Since a long period, GCS has been a rational approach for classification of patients with head injury. Since majority of TBI patients need intubation in view of airway protection, the influence of drugs is a hurdle in scoring of patients. Hence, the need for a scoring system, which utilizes the morphological criteria based on the radiological imaging, that is, the CT scan, is paramount. Various studies have verified the role of CT scores in predicting the mortality of patients following TBI. ${ }^{19}$ Since, CT imaging is the easiest tool for predicting mortality and the functional outcome in TBI patients, we aimed at using a scoring system which could overcome the drawbacks of $\mathrm{GCS}^{20}$ and provide better information to the health caregivers. Marshall score and Rotterdam score are being used for the same; the latter is a recently developed scoring system for the same. ${ }^{17}$

The Rotterdam score differentiates between the types of mass lesions and recognizes more favorable prognosis associated with epidural hematomas. ${ }^{21-23}$ We thus aimed to determine whether the Rotterdam CT score can be utilized for risk stratification of mortality in pediatric and adult age groups with TBI. In our study, we found a significant difference in the CT imaging findings of pediatric and adult TBI. The most common CT finding in both the groups was that of basal cistern and contusions. This result was not in consistence with other studies where depressed fracture and SDH were common in pediatrics, while SDH and traumatic SAH in adults. ${ }^{24}$ We found a lower Rotterdam score of $1.99 \pm 0.75$ for pediatrics, while a statistically significant score of $2.22 \pm 0.86$ for adults. The result was in consistence with other studies as well. ${ }^{24}$ However, both the groups had a statistically similar severity of injury as measured by the GCS scoring system. The difference in CT findings may be attributed to anatomical characteristics. Among the various differences, a few to mention are as follows: the mechanical effect of forces generated during injury causing fracture of cranial vault in adults ${ }^{16}$ and skull in pediatrics, ${ }^{14}$ brain cerebrospinal fluid (CSF) volume explaining the relative movement of brain at the time of impact, ${ }^{25}$ decrease incidence of intracranial fractures with age, ${ }^{16}$ and strength of neck and head varying with age. ${ }^{14}$ The net effect of these factors leads to the formation of a complex injury pattern in adults. Hence, clinical outcome is better in young patients. The Rotterdam scoring system takes into account the radiological criteria of basal cistern status, midline shift, subarachnoid hemorrhage, and mass lesion. This score is directly related to mortality. In our study, the score of 2 was most common for the adult age group, followed by 3 and then 1, while the most common score for pediatrics was 2 , followed by 1 and later 3 . The score was statistically significant, with a lower score for pediatric TBI patients. This indicates lower mortality ratio, which was in accordance with other studies ${ }^{18,24}$ (-Table 3 ). Thus, concluding that the Rotterdam CT score can be used for mortality risk stratification in TBI patients. 
Table 2 Demographics, mode of injury, and CT findings

\begin{tabular}{|c|c|c|c|c|c|c|c|c|}
\hline & & \multicolumn{2}{|c|}{ Adult $(N=939)$} & \multicolumn{2}{|c|}{ Pediatric $(N=211)$} & & Total & $p$-Value \\
\hline \multicolumn{2}{|l|}{ Age (y) } & \multicolumn{2}{|c|}{$36.37 \pm 15.80$} & \multicolumn{2}{|c|}{$6.65 \pm 3.84$} & & & $<0.001$ \\
\hline \multicolumn{2}{|l|}{ Percentage } & \multicolumn{2}{|c|}{$81.65 \%(n=939)$} & \multicolumn{2}{|c|}{$18.35(n=211)$} & & & \\
\hline & & $N$ & $\%$ & $N$ & $\%$ & & & \\
\hline Gender & Female & 145 & 15.44 & 49 & 23.22 & & 194 & 0.009 \\
\hline 1) & Male & 794 & 84.56 & 162 & 76.78 & & 956 & 1) \\
\hline \multicolumn{2}{|l|}{ Male:Femalew } & \multicolumn{2}{|r|}{5.48} & \multicolumn{2}{|r|}{$3.31: 1$} & & & \\
\hline $\begin{array}{l}\text { Mode of } \\
\text { injury }\end{array}$ & Assault & 57 & 6.07 & 2 & 0.95 & & 59 & 0.004 \\
\hline 1) & Fall of heavy object on head & 4 & 0.43 & 1 & 0.47 & & 5 & 0.762 \\
\hline 1) & Fall from height & 163 & 17.36 & 157 & 74.40 & & 320 & 0.001 \\
\hline 1) & Road traffic accident & 690 & 73.48 & 49 & 23.22 & & 739 & 0.001 \\
\hline 1) & Sports & 5 & 0.53 & 2 & 0.95 & & 7 & 0.833 \\
\hline 1) & Other & 9 & 0.96 & & 0 & & 9 & 0.375 \\
\hline 1) & Unknown & 11 & 1.17 & & 0 & & 11 & 0.235 \\
\hline CT finding & Abnormal & 715 & 76.14 & 146 & 69.19 & & 861 & 0.04 \\
\hline 1) & TSAH & 142 & 15.12 & 28 & 13.27 & & 170 & 0.56 \\
\hline 1) & $\mathrm{EDH}$ & 137 & 14.59 & 29 & 13.74 & & 166 & 0.83 \\
\hline 1) & ASDH & 156 & 16.61 & 13 & 6.16 & & 169 & $<0.001$ \\
\hline 1) & Contusion & 480 & 51.12 & 75 & 35.55 & & 555 & $<0.001$ \\
\hline 1) & Other findings & & 0.00 & & 0.00 & & & \\
\hline 1) & Depressed fracture & 43 & 4.58 & 22 & 10.43 & & 65 & 0.002 \\
\hline 1) & Pneumocephalous & 33 & 3.51 & 15 & 7.11 & & 48 & 0.03 \\
\hline 1) & Midline Shift & & & & & & & \\
\hline 1) & $\geq 5 \mathrm{~mm}$ & 71 & 7.56 & 5 & 2.37 & & 76 & 0.01 \\
\hline 1) & $0-4 \mathrm{~mm}$ & 90 & 9.58 & 8 & 3.79 & & 98 & 0.01 \\
\hline 1) & $N$ & 778 & 59 & 198 & 63.03 & & 687 & $<0.001$ \\
\hline Basal cisterns & & No & $\%$ & No & $\%$ & No & $\%$ & \\
\hline 1) & Absent & 58 & 6.18 & 5 & 2.37 & 63 & 5.48 & 0.042 \\
\hline 1) & Compressed/obliterated & 130 & 13.84 & 10 & 4.74 & 140 & 12.17 & $<0.001$ \\
\hline 1) & Open & 751 & 79.98 & 196 & 92.89 & 947 & 82.35 & $<0.001$ \\
\hline 1) & Total & 939 & 100.00 & 211 & 100.00 & 1150 & 100.00 & \\
\hline $\begin{array}{l}\text { No. of CT } \\
\text { findings }\end{array}$ & 1 & 619 & 65.92 & 151 & 71.56 & 770 & 137.49 & \\
\hline 1) & 2 & 157 & 16.72 & 24 & 11.37 & 181 & 28.09 & \\
\hline 1) & 3 & 75 & 7.99 & 5 & 2.37 & 80 & 10.36 & \\
\hline 1) & 4 & 31 & 3.30 & 2 & 0.95 & 33 & 4.25 & \\
\hline 1) & 5 & 4 & 0.43 & 1 & 0.47 & 5 & 0.90 & \\
\hline
\end{tabular}

Abbreviations: ASDH, acute subdural hematoma; $\mathrm{EDH}$, extradural hematoma; $\mathrm{N}$, number of patients or findings; TSAH, traumatic subarachnoid hemorrhage; \%,percentage.

Note: Bold values represent significant values.

\section{Limitations}

We studied prognosis on the basis of the earliest radiographic findings, thus requiring further long-term studies.
There could have been interobserver bias based on a difference in reporting of the CT image. We did not include the Marshall score along with the Rotterdam score for prediction of prognosis. 
Table 3 Comparative Rotterdam score of adult and pediatric age groups from a previous study

\begin{tabular}{|c|c|c|c|c|c|c|c|}
\hline \multirow[b]{2}{*}{ Rotterdam-score } & \multicolumn{3}{|c|}{ Sarkar et al $(2014)^{24}$} & \multicolumn{4}{|c|}{ Current study } \\
\hline & Adults & Pediatrics & $p$-Value & $\begin{array}{l}\text { Adults } \\
(N=939)\end{array}$ & $\begin{array}{l}\text { Pediatrics } \\
(N=211)\end{array}$ & Total & $p$-Value \\
\hline 1 & 46 & 37 & 0.001 & 129 & 45 & 174 & 0.008 \\
\hline 2 & 378 & 202 & $<0.001$ & 583 & 135 & 718 & 0.66 \\
\hline 3 & 335 & 70 & $<0.001$ & 131 & 23 & 154 & 0.28 \\
\hline 4 & 52 & 15 & 0.322 & 45 & 4 & 49 & 0.09 \\
\hline 5 & 22 & 7 & 0.756 & 32 & 0 & 32 & 0.013 \\
\hline 6 & 00 & 0 & & 19 & 4 & 23 & 0.87 \\
\hline Mean & & & & 2.22 & 1.99 & & $<0.001$ \\
\hline Standard deviation & & & & 0.857 & 0.746 & & 1 \\
\hline
\end{tabular}

\section{Conclusion}

We, thereby, conclude the immense predictive power of the Rotterdam score for prognostication of head injury patients and required action by healthcare personnel. After TBI, both the age groups exhibit separate patterns of intracranial injuries. The adult age group is more prone to hemorrhage and midline shift, while the pediatric age group is more prone to skull fracture and EDH which are ultimately related to better prognosis. These differences in pattern of injury may be attributed to the anatomical and physiological parameters of both the age groups. Hence, concluding that pediatric age group has better prognosis in terms of survival as compared with adult head injury patients. Thus, justifying the role of the Rotterdam CT score in terms of providing prognosis of TBI patients, clinical care, and further trial opportunities.

\section{Authors' Contributions}

All authors were involved in the collection of data, management of the patients, and preparation of manuscript. The manuscript has been read and approved by all the authors, and each author believes that the article represents honest work.

\section{Conflict of Interest}

None declared.

\section{References}

$1 \mathrm{NIH}$. Consensus conference. Rehabilitation of persons with traumatic brain injury. NIH consensus development panel on rehabilitation of persons with traumatic brain injury. JAMA 1999;282:974-983

2 Langlois JA, Marr A, Mitchko J, Johnson RL. Tracking the silent epidemic and educating the public: CDC's traumatic brain injury-associated activities under the TBI Act of 1996 and the Children's Health Act of 2000. J Head Trauma Rehabil 2005;20(3):196-204
3 WHO. World Report on Road Traffic Injury Prevention. Geneva: World Health Organization; 2004

4 Tabish SA, Nabil S. Traumatic brain injury: the neglected epidemic of modern society. International Journal of Science and Research (IJSR) 2014;3(12):382-406

5 Central department for Statistics and information. Annual statistical books (2009, 31 July). Available at: http://www.cdsi. gov.sa. Accessed November 2019

6 UNICEF: Statistics and monitoring. (2009, 30 July);Available at:http://www.unicef.org/statistics/index_step1.php.Accessed February, 6, 2020

7 Kapp C. Who acts on road safety to reverse accident trends -traffic accidents kill 1.26 million people each year, 2nd leading cause of death among those aged 15-29. Lancet. 4,362,1125; 2003; doi: 10.1016/s0140-6736(03)14501-1.

8 Gururaj G. Epidemiology of traumatic brain injuries: Indian scenario. Neurol Res 2002;24(1):24-28

9 Gururaj G. Road traffic deaths, injuries and disabilities in India: current scenario. Natl Med J India 2008;21(1):14-20

10 Narayan RK, Michel ME, Ansell B, et al. Clinical trials in head injury. J Neurotrauma 2002;19(5):503-557

11 Pfenninger J, Santi A. Severe traumatic brain injury in children-are the results improving? Swiss Med Wkly 2002;132(9-10):116-120

12 Raphaely RC, Swedlow DB, Downes JJ, Bruce DA. Management of severe pediatric head trauma. Pediatr Clin North Am 1980;27(3):715-727

13 Lang DA, Teasdale GM, Macpherson P, Lawrence A. Diffuse brain swelling after head injury: more often malignant in adults than children? J Neurosurg 1994;80(4):675-680

14 Ommaya AK, Goldsmith W, Thibault L. Biomechanics and neuropathology of adult and paediatric head injury. Br J Neurosurg 2002;16(3):220-242

15 Eggensperger Wymann NM, Hölzle A, Zachariou Z, Iizuka T. Pediatric craniofacial trauma. J Oral Maxillofac Surg 2008;66(1):58-64

16 Roeder RA, Thaller S. Unique features of the pediatric craniofacial anatomy. J Craniofac Surg 2011;22(2):392-394

17 Maas AI, Hukkelhoven CW, Marshall LF, Steyerberg EW. Prediction of outcome in traumatic brain injury with computed tomographic characteristics: a comparison between the computed tomographic classification and combinations of computed tomographic predictors. Neurosurgery 2005;57(6):1173-1182

18 Liesemer K, Riva-Cambrin J, Bennett KS, et al. Use of Rotterdam CT scores for mortality risk stratification in 
children with traumatic brain injury. Pediatr Crit Care Med 2014;15(6):554-562

19 Maas AI, Steyerberg EW, Butcher I, et al. Prognostic value of computerized tomography scan characteristics in traumatic brain injury: results from the IMPACT study. J Neurotrauma 2007;24(2):303-314

20 Saatman KE, Duhaime AC, Bullock R, Maas AI, Valadka A, Manley GT; Workshop Scientific Team and Advisory Panel Members. Classification of traumatic brain injury for targeted therapies. J Neurotrauma 2008;25(7):719-738

21 Hirsch W, Schobess A, Eichler G, Zumkeller W, Teichler H, Schluter A. Severe head trauma in children: cranial computer tomography and clinical consequences. Paediatr Anaesth 2002;12(4):337-344
22 Lobato RD, Cordobes F, Rivas JJ, et al. Outcome from severe head injury related to the type of intracranial lesion. A computerized tomography study. J Neurosurg 1983;59(5):762-774

23 The Brain Trauma Foundation Guidelines. Computed tomography scan features. J Neurotrauma 2000;17(6-7):597-627

24 Sarkar K, Keachie K, Nguyen U, Muizelaar JP, Zwienenberg-Lee M, Shahlaie K. Computed tomography characteristics in pediatric versus adult traumatic brain injury. J Neurosurg Pediatr 2014;13(3):307-314

25 Courchesne E, Chisum HJ, Townsend J, et al. Normal brain development and aging: quantitative analysis at in vivo MR imaging in healthy volunteers. Radiology 2000;216(3):672-682 